\title{
ECOLOGY OF INFOCHEMICAL USE BY NATURAL ENEMIES IN A TRITROPHIC CONTEXT
}

\author{
Louise E. M. Vet and Marcel Dicke \\ Department of Entomology, Wageningen Agricultural University, PO Box 8031, 6700 \\ EH Wageningen, The Netherlands
}

KEY WORDS: predators, parasitoids, searching behavior, learning, evolutionary theory, integrated pest management

\section{PERSPECTIVES AND OVERVIEW}

Parasitoids and predators of herbivores have evolved and function within a multitrophic context. Consequently, their physiology and behavior are influenced by elements from other trophic levels such as their herbivore victim (second trophic level) and its plant food (first trophic level) (126). Natural enemies base their foraging decisions on information from these different trophic levels, and chemical information plays an important role. This review is restricted to the ecology of chemical information from the first and second trophic levels. The importance of so-called infochemicals, a subcategory of semiochemicals, in foraging by parasitoids and predators has been well documented (e.g. reviewed in 31, 78, 111, 183, 185), and we do not intend to repeat the details. But because of a lack of testable hypotheses, all this research is conducted rather haphazardly: the total puzzle of infochemical use has not been solved for any natural enemy species. Here we approach the use of infochemicals by natural enemies from an evolutionary and ecological standpoint. Our basic concept is that information from the first and second trophic levels differs in availability and in reliability, a difference that shapes the way infochemicals are used by a species. We generate hypotheses on (a) 


\section{VET \& DICKE}

the relative value of infochemicals from the first and second trophic level and on $(b)$ the function of plasticity in the responses, especially through learning, in different species of natural enemies. Using this ecological approach, we evaluate the status of and prospects for application of infochemicals in pest management. Figure 1 depicts the major concepts of this review.

\section{CHEMICAL INFORMATION IN TRITROPHIC INTERACTIONS}

Price et al (126) stated that interactions between herbivores and their host plants and between herbivores and their natural enemies can only be understood when considered within a tritrophic context. The importance of tritrophy is reflected in the searching behavior of natural enemies of herbivores: predators and parasitoids. Information from plants is important in their searching process. A sequence of responses to different information sources brings the foraging animal closer and closer to its potential victim. Chemical information plays an important role in which plant volatiles mediate searching behavior, especially at longer distances, while the importance of herbivorederived chemicals increases with decreasing distance from the victim. The how of this searching process has been reviewed extensively, especially for parasitoids (e.g. 50, 111, 113, 183-185). This knowledge has been used to understand the adaptive significance, the why, of foraging strategies of natural enemies $(125,141,166)$.

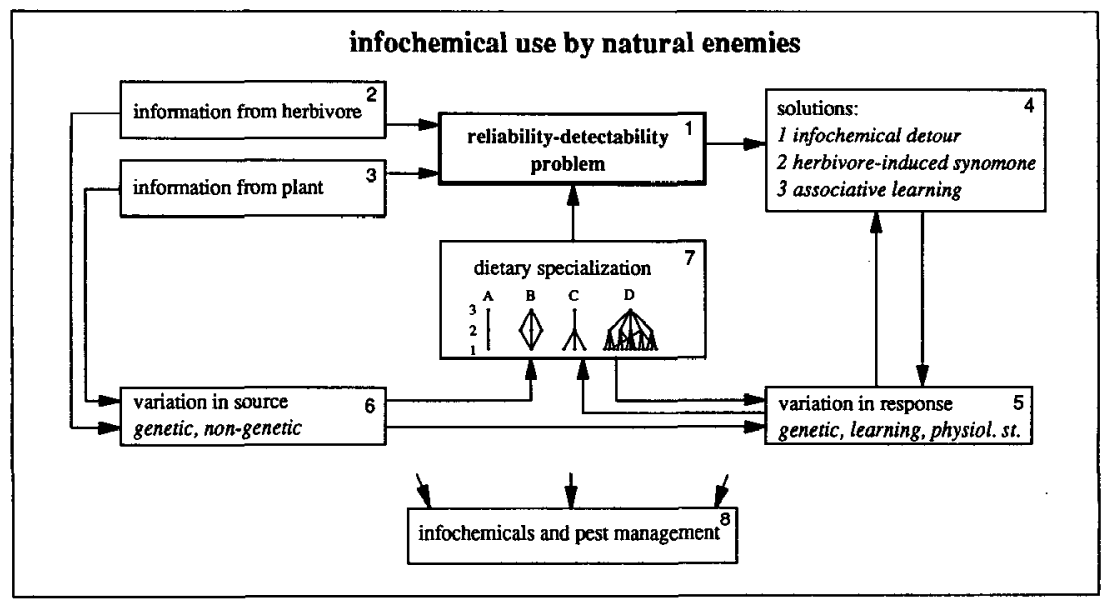

Figure 1 Flow diagram of the major concepts discussed in this review. The central idea is the reliability-detectability problem. The arrows specify an influence or determination of one factor upon another and the direction in which this occurs. Numbers indicate the order in which the topics are discussed in the text. 


\section{Sources of Chemical Cues}

Abundant information on sources of chemical cues and the behavior they elicit in foraging natural enemies is available for parasitoids (reviewed in 26, $113,133,183-185,197)$, which contrasts to the relatively little information available for predators $(31,48,54,184)$. We limit ourselves to a brief summary.

Chemical information can originate from the herbivore, from its food, from organisms associated with herbivore presence, or from interactions between these sources. Just about any product of a herbivore can potentially provide a chemical cue for its attackers: feces, cuticle, exuviae, secretions of mandibular and accessory glands, pheromones, honeydew, body scales, or hemolymph. Also, the food of the herbivore, such as flowers or leaves, can give specific chemical information. Herbivore-associated organisms, such as microbes, may also be an important source of chemical information. Additional chemical information may result from interactions between herbivore, food, and/or associated organisms.

In the present review, we explore causes and functions of variation in the use of chemical information from different trophic levels.

\section{Infochemical Terminology}

The Nordlund \& Lewis (112) semiochemical (the chemicals involved in the chemical interations between organisms) terminology was changed recently from a bitrophic into a tritrophic context (29). Information-conveying chemicals were termed infochemicals (Figure 2), which constitute a subcategory of semiochemicals.

All terms are context-specific rather than chemical-specific $(29,112)$ : parasitoids may use a pheromone of their host as kairomone, and the term used depends on whether the considered interaction is intra- or interspecific. Similarly, allelochemicals that result from a herbivore-plant interaction and that attract natural enemies of the herbivore may be viewed in the context of a first-third level interaction or in a second-third level interaction. In the former, allelochemicals function as synomones and in the latter as kairomones.

\section{Use of Stimuli from Second and First Trophic Level: Reliability vs Detectability}

RELIABILITY-DETECTABILITY PROBLEM Natural enemies are faced with a great variety of stimuli they may use to locate their victim, even when one considers only one sensory modality, i.e. chemoreception. Both plants and herbivores produce odors and thus potential information. The appropriateness and usability of information ultimately depends on two factors: $(a)$ its reliability in indicating herbivore presence, accessibility, and suitability and $(b)$ the 


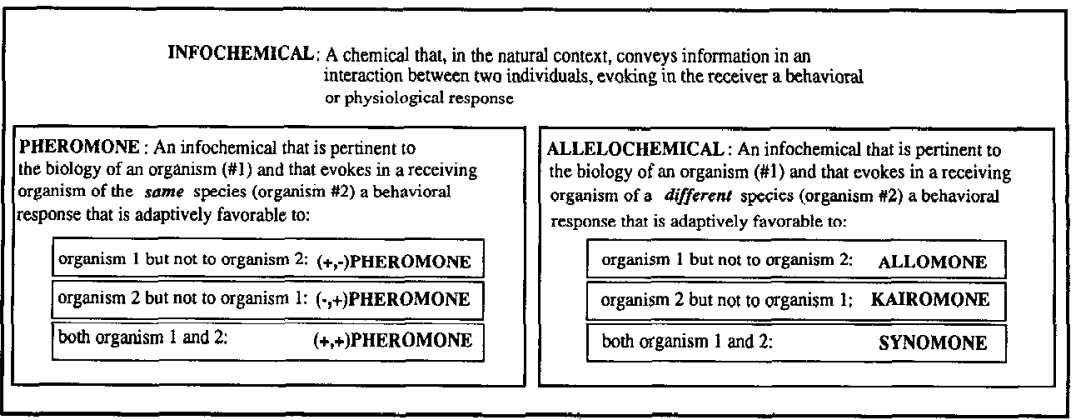

Figure 2 Infochemical terminology (cf. 29).

degree to which stimuli can be detected. We assume that the use of information that is both reliable and easy to detect enhances searching efficiency and consequently Darwinian fitness (see also 180, 192).

Stimuli derived from the herbivore itself are generally the most reliable sources of information. Ideally, the infochemicals should tell natural enemies whether a herbivore is present, which species it belongs to, how many there are, whether the herbivore should be parasitized or eaten, and whether it is readily accessible or hidden. Parasitoids whose host continues to develop, and predators who search for an oviposition site, also need to know whether the food plant is suitable for the development of their offspring. In fact, the more intimately dependent on the herbivore the natural enemy is, the more specific is the information it needs.

However, use of herbivore-derived stimuli is often limited by low detectability, especially at longer distances $(31,162)$. Stimuli from plants, on the other hand, are usually more readily available because of the plants' relatively larger biomass but are less reliable predictors of herbivore presence. Reliability of plant cues depends on the predictability of plant infestation over space and time. So natural enemies are challenged to combine the advantageous characteristics of information from both trophic levels. We hypothesize that detectability of stimuli from the second trophic level puts a major constraint on the evolution of herbivore location by their natural enemies. Natural enemies may deal with the reliability-detectability problem in three ways: (a) by resorting to use of more conspicuous infochemicals from herbivore stages different from the one under attack (infochemical detour), $(b)$ by focusing their responses on stimuli created by specific interactions of the herbivore and its food, and $(c)$ by learning to link easy-to-detect stimuli to reliable but hard-to-detect stimuli.

INFORMATION FROM THE HERBIVORE Low detectability is a major constraint for the usability of information released by the second trophic level for 
two reasons. First of all, herbivores are small components of a complex environment, and if they produce odors at all, it will be in minute quantities. Secondly, continuous selection for inconspicuousness acts on herbivores as a way to escape parasitization and predation. Minimization of odor emission is one way to accomplish this goal. Although insects are famous for their sensitive chemosensors that detect minute concentrations, this high sensitivity can be expected to have evolved mainly in intraspecific interactions in which selection pressures coincide and qualitative variation in the signal is very low (91).

While communicating intraspecifically through pheromones, herbivores are often much more conspicuous to their natural enemies that exploit these pheromones as kairomones in long-distance herbivore location $(55,197)$. A well-known example is that of predators and parasitoids of bark beetles that respond to volatile aggregation pheromones of their victims (e.g. 100, 121, 189). Similarly, parasitoids exploit the sex pheromones of their hosts as kairomones $(99,108)$.

Apart from these pheromones, herbivore odors are difficult to detect at longer distances, and, as expected, herbivore-derived cues become more important the closer foraging natural enemies come to their victim. For example, stimuli used in habitat location (i.e. long-range) are generally plant volatiles or herbivore pheromones (184), while stimuli used in host location (i.e. short-range) are nonvolatile herbivore products (197). The literature documents only a few examples of natural enemies that are attracted from a distance to volatiles from the herbivore (other than pheromones) $(103,107$, 165).

Herbivores have to feed and defecate, which unavoidably results in emission of volatiles that may reveal their presence. Herbivores have different behaviors that may have evolved to limit this supply of chemical information. 1. Emission can be avoided through a concealed life-style, e.g. by living in mines or galls, or by selecting those plant species, plant individuals, or plant parts where volatile production is minimal-an enemy-free space solely based on olfaction [obviously under the constraint of sufficient nutritive quality (126)]. In such cases, other sensory modalities such as vision may become relatively more important in finding the herbivore victim (153). 2. Herbivores may desert locations emitting the information. Feeding behavior of Pieris rapae larvae is characterized by frequent interruptions during which the larvae move to another feeding site (92). This movement may fool larval parasitoids into searching in the wrong place (105) as they are attracted to the feeding damage of their host $(72,104) .3$. The source of the chemical information itself may be discarded $(125,185)$. Hence, herbivore location by natural enemies is constrained by selection for inconspicuousness in the herbivore. The more successful the herbivore is in avoiding information conveyance, the more natural enemies have to turn to information from plants. 


\section{VET \& DICKE}

One might think that natural enemies attacking nonfeeding stages of the herbivore, such as eggs and pupae, cannot exploit information from feeding and defecation by hosts or prey. However, the enemies may solve the reliability-detectability problem by resorting to information from other stages (infochemical detour), provided that these stages supply reliable information on the presence of the herbivore stage of interest. For instance, egg parasitoids use pheromones of the adult stage of their host (e.g. 108). If herbivore stages occur discretely, the natural enemy can only use information from a stage preceding the stage under attack, under the constraint of the time elapsing between the stages. An egg-larval parasitoid of the apple maggot fly exploits the adult fly's oviposition-deterring pheromone present on the fruit, while a closely related parasitoid species that attacks late larval stages does not (127). Analogously, we may expect pupal parasitoids to respond to information from feeding larvae, provided that the pupation site is close to the larval feeding site. Perhaps larval dispersal to remote sites for pupation is a way to avoid such information conveyance. If feeding and nonfeeding stages co-occur, natural enemies could potentially utilize information from several stages, including stages that follow the stage under attack. Under such conditions, egg parasitoids can be expected to use feeding-related infochemicals, but we know of no examples.

INFORMATION FROM PLANTS The value of plant information strongly depends on the degree of herbivore infestation. If this infestation is predictably very high, plant information is reliable. Damage by herbivores increases the emission of plant volatiles enormously $(30,32,163)$, and natural enemies attacking feeding stages readily exploit this information. They can differentiate between herbivore-infested and uninfested plants (e.g. 27, 38, 135, $141,161,173)$, and in several cases the attractive chemicals are shown to be released by the plant $(31,32,135,163)$. Some of the chemicals disseminated from the infested plants merely result from mechanical disruption of plant cells and thus are nonspecific for the herbivore. However, other plant volatiles that are released upon damage are specific indicators of herbivore identity $(31,32,163,164)$. These are not released upon mechanical damage but only after specific herbivore damage. If these chemicals attract natural enemies whose activities are favorable to the plant, they are called herbivoreinduced synomones. Herbivore-induced synomones provide a major solution to the reliability-detectability problem. Corn seedlings release large amounts of volatile terpenoids after damage inflicted by Spodoptera caterpillars, which attract the larval parasitoid Cotesia marginiventris. Induction of these synomones can be simulated by treating leaves with caterpillar oral secretions (163). Similarly, the predatory mite Phytoseiulus persimilis is attracted by spider mite-induced synomones produced by bean or cucumber plants $(31,32)$. Emission of this synomone is not restricted to the damaged 
site, but is released systemically by the whole plant under attack, i.e. by undamaged leaves as well (31). This action greatly increases the size of the odor plume and thus the chance for a natural enemy to find the infested plant.

Apart from being specific for the damaging herbivore species, herbivoreinduced synomones can also be plant-species specific $(31,160)$ and cultivarspecific (156). The ability of a natural enemy to differentiate between different plant species or cultivars can be functional as plants may affect natural enemy fitness directly, e.g. through the interference of hairs and glands with foraging behavior $(114,171)$, and indirectly, e.g. through the plant's suitability for herbivore development (5). However, the ability to distinguish between the different plant species demands intricate sensory and neural processing. Plant volatiles are known for their diversity in chemical composition and complexity of blends, their changeability in time, and their dependence on rearing conditions (91, 188 and references therein). Natural enemies may cope with this complexity by reducing their focus on a limited set of chemicals that, through experience, have been shown to be characteristic for a particular plant-herbivore combination $(35,80,160,163,164,176)$.

In conclusion, natural enemies that attack feeding stages of herbivores can be expected to use well-detectable and reliable herbivore-induced synomones. When release of these chemicals is limited, e.g. because of a concealed life-style of the herbivore, or absent, e.g. in nonfeeding herbivore stages, the reliability-detectability problem has other solutions, i.e. to resort to information from other stages or, as discussed next, to learn easy-to-detect stimuli.

\section{INTRASPECIFIC VARIATION IN RESPONSE}

Foraging behavior in insects is often variable within and among populations. Variation can originate at both the genotypic and the phenotypic level $(47,66$, $130,149)$. These causes of variation are not always independent. An organism's phenotypic plasticity [i.e. modification of the phenotype in response to different environmental conditions (cf. 181)] may itself have a genetic basis (e.g. 150, 181). Responses of natural enemies to infochemicals vary intraspecifically. With regard to genetic variation, this statement remains practically unconfirmed (124). Researchers have not even begun to document genetic variability in response to infochemicals within and between populations, let alone try to estimate its magnitude, which is important for understanding the process of evolution (182).

Nongenetic variation in response to infochemicals resulting from learning processes or variation in the physiological state of the animal has been explored more extensively. In this section, we review this knowledge and explore how this nongenetic variation affects the reliability-detectability problem. 


\section{Learning}

LEARNING IN PARASITOIDS AND PREDATORS Learning is an important source of behavioral variability in foraging natural enemies. Responses to chemical and visual cues change with experience. Learning to respond to cues can be adaptive when the environment is unpredictable between generations but predictable during the organism's lifetime (151), or, in general, when the individual encounters an environment that varies in a regular and predictable way (118). Such situations occur for natural enemies when, for example, mothers and daughters forage for different herbivore resources or when the abundance of different herbivores and their microhabitats fluctuate in time and/or space in a regular fashion. Although many aspects of learning in parasitoids resemble those in bees and phytophagous insects, the study of learning by natural enemies is of special interest because it takes place in a more complex tritrophic context rather than in a bitrophic one. Another difference between learning in foraging bees and natural enemies is directly related to the reliability-detectability problem: bees learn to forage for items that have evolved to expose themselves, i.e. flowers, while natural enemies learn to forage for items that have evolved to hide themselves.

Learning can be specified by three criteria (118). For parasitoids, it is reported that $(a)$ behavior can change in a repeatable way through experience (176) and $(b)$ learned responses can be forgotten (e.g. 119, 174). A third criterion, $(c)$ that behavior changes gradually with continued experience up to an asymptote, is difficult to apply to parasitoid learning because learning often occurs very rapidly [in seconds or after a single oviposition (e.g. 160, 164)], resembling single-trial learning (i.e. learning in which behavior changes after one experience and changes little with further experience).

Parasitoids may learn a whole gamut of characteristics of the host's environment. These characteristics can involve odor of the host's food (e.g. 35, 174, 199), the color and form of the host's environment (e.g. 195, 196 and references therein), the part of the plant in which the host resides, or even the exact site of a host (192).

Learning of odors Odor learning in parasitoids is under increasing investigation (for recent reviews, see 176, 177). Preadult learning, as a consequence of development in a particular host and its food, can influence responses to odors by the adult (e.g. 146), although it is much less common and pronounced compared to learning during the adult stage (reviewed in 176). Learning during the adult life can influence odor responses in a distinct way; associative learning, whereby responses to stimuli are newly acquired or enhanced by linking them to a reinforcing stimulus, is a frequently suggested mechanism (e.g. $35,80,160,164,174,176)$. Current knowledge indicates that for 
parasitoids foraging for hosts the reinforcing stimuli in associative learning are always host derived $(78,177)$.

Investigations on learning related to foraging for prey by arthropod predators are limited. Predator learning of olfactory cues has mainly been reported for social Hymenoptera such as ants and wasps, in which learning is used for recognition of brood and nestmates (e.g. 15, 61, 64). Examples of arthropod predators learning odors of the environment of their herbivorous prey or of the prey itself are few (2). Recent research showed that the preference of predatory mites for odors of prey-infested plants is partly determined by previous foraging experience, but the exact learning mechanism remains unclear ( 31 , 33).

EVOLUTION OF PLASTICITY IN RESPONSES TO INFOCHEMICALS Where and when do we expect learning to influence responses to kairomones and synomones and how can learning help to solve the reliability-detectability problem for foraging natural enemies? Before addressing these questions, we introduce some ideas expressed in a recent paper (177) on a conceptual model of variability in responses. For each stimulus perceived by a natural enemy in a specific physiological state, a potential response is postulated that can range from zero to some maximum set by physiological constraints. The strength of this response potential in the naive animal is set by natural selection. High response potentials are expected for stimuli that are consistently and predictably used in host location. The intrinsic variability of a response is believed to depend on the strength of the response potential. Strong responses are less variable than weak ones. Among other things, the model specifies when and how learning modifies the strength and variability of a response. It predicts that, in general, learning not only increases the mean of a response but simultaneously decreases its variability $(177,178)$. This prediction has interesting evolutionary implications because variability may influence the heritability of responses and therefore affect how selection acts on foraging behavior (117a). A further argument is that learning has more impact on initially weak responses than on initially strong ones. Several stimuli with a high response potential will even evoke responses that are intrinsically invariable and not subject to modification by experience.

Hypothesis Applying these ideas to infochemicals, we argue that herbivorederived products are high-response stimuli because they are intimately and reliably linked with the material presence of a herbivore. As such, changes in response to these reliable stimuli should be relatively conservative in both an ontogenetic and an evolutionary sense. Environmental cues such as plant volatiles, on the other hand, give only indirect information on herbivore presence and suitability, information that is often less predictable and reliable. 
The most reliable plant-derived information is a specific herbivore-induced synomone. The reliability of information derived from uninfested plants is ultimately determined by the process of plant selection and infestation by the herbivore. We therefore predict that, in general, responses to herbivorederived products are more congenitally fixed and strong, while responses to plant volatiles are more plastic and initially weaker. Indeed, inexperienced female parasitoids reportedly show strong responises to host kairomones (especially contact kairomones) (e.g. 63, 157). In fact, although not explicitly mentioned, the majority of kairomone studies (especially less recent ones) have most likely been conducted with young, naive animals. Some reports explicitly show that experience has no effect on the responses to kairomones: rearing on different host species does not affect the kairomone response in Trichogramma minutum egg parasitoids (200), and neither does oviposition experience (45). Similarly, in other parasitoid species, responses to kairomones are not or are only slightly modifiable $(63,83,152,157,198)$. One suggestion is that the degree to which responses to kairomones can still be modified by experience depends on the degree of host specificity: the greater the specificity the less is the need for learning (86). In a later section (Dietary Specialization and Infochemical Use), we elaborate on how specificity affects the way infochemicals are used, including this need for learning.

In contrast to the generally fixed responses to kairomones, responses to plant volatiles are indeed more variable and subject to learning. Responses to synomones reportedly depend on the way the parasitoid has been reared (59, 172). However, plant volatiles are usually learned during adult foraging in which reliable host-derived stimuli are associated with more unreliable but more detectable synomones $(35,80,163,164,176,177)$. Associations made during oviposition can strongly influence responses to synomones $(35,199)$. Responses to host plant odors in Trichogramma spp. are, unlike the responses to contact kairomones, influenced by oviposition experience (73).

Function and mechanisms of learning: when to learn and how? Incorporation of the learned information into the searching process is functional if it enhances subsequent herbivore encounter rates. On the other hand, learning may have costs in terms of foraging time, as responses are not immediate. When information useful to foragers is reliable and occurs highly predictably within and over generations, selection may cause responses to become congenitally fixed. However, this phenomenon is restricted to situations in which storage of information is more economical compared to learning, and in which no physiological limitation prevents encoding of all the information. Currently, both restrictions are still under discussion (118).

The speed, reversibility and mechanism of learning may be related to the frequency with which the individual has to switch resources in its lifetime. If 
daughters need to forage for items different from what their mothers forage for, but the situation remains unaltered during the lifetime of the individual, fast and irreversible changes through sensitization or imprinting would suffice, and single-trial learning would be functional. More complex and reversible learning processes such as associative learning may be expected when individuals are frequently faced with different foraging situations. Sensitization could be a way to learn herbivore-induced synomones (72). After all, these synomones are already the product of a specific association of a herbivore and plant, and so it seems superfluous for the natural enemy to repeat this association through associative learning.

Habituation (i.e. a waning of the response to a stimulus with repeated exposure to that stimulus) may influence responses to kairomones (e.g. 19, $45,157,190,200)$. It is an important process that is thought to be the underlying mechanism making parasitoids eventually disperse from patches if foraging is not or is no longer profitable (190). Habituation to synomones is still unstudied. However, responses to synomones are often learned and waning of these learned responses (in the absence of the stimulus and of repeated reinforcement) has been demonstrated for several species and is probably common $(35,73,78,174)$. Its function is probably similar to habituation to kairomones, but at a higher foraging level-i.e. dispersal at the plant or plant community level.

In summary, herbivore-produced kairomones, in particular contact kairomones, generally evoke strong and congenitally fixed responses, while responses to plant volatiles are more plastic. Reliable host-derived stimuli serve as reinforcers in associative learning through which parasitoids acquire or enhance responses to less reliable but more detectable plant volatiles. This way, parasitoids can safely control the use of information coming from plants.

\section{Physiological State}

PHYSIOLOGICAL STATE AND FORAGING BEHAVIOR The internal state of an animal influences its foraging behavior $(7,23,98,148,159)$. Foraging by predators is affected by lack of food $(62,139)$, and foraging for hosts by parasitoids is affected by egg-load (e.g. 21, 36, 128). The general connotation derived from experimental data and models is that selectivity of foraging insects decreases when deprivation increases $(17,24,65,89,101,139)$. Does this change in selectivity reflect the required reliability of information and thus the way natural enemies use infochemicals?

PHYSIOLOGICAL STATE AND RESPONSES TO INFOCHEMICALS Food deprivation and egg-load influence natural enemies' responses to infochemicals $(27,79,113,141)$. In addition to general food deprivation, deficiency in specific nutrients [specific hunger (25)] may also affect responses to in- 


\section{VET \& DICKE}

fochemicals in insects $(46,74,122)$. Examples for natural enemies are restricted to predatory mites. Carotenoid-deficiency greatly affects the response of these mites to kairomones. Predators that have carotenoids available respond selectively to the kairomone of the preferred prey species only. Carotenoid-deficient predators, on the contrary, also respond to the kairomones of less-preferred prey species that contain carotenoids $(27,28)$. This expanded range of kairomone responses under suboptimal conditions leads to expansion of diet breadth, which is analogous to predictions of the classical optimal diet models: when encounter rate with profitable prey is low, animals should not be selective in their prey choice (e.g. 87). The effect of specific hunger in mites is yet another example that shows that animals may not only maximize energetic input per unit of time, as is assumed by most optimal diet models, but that their foraging decisions may also be determined by nutritional constraints (e.g. 49).

VARIATION IN SENSORY PROCESSING As foraging is generally guided by infochemicals, natural enemies rely heavily on what their chemoreceptors tell them. However, the same chemoreceptors may tell them different things at different times; the peripheral sensory input of insects varies $(10,91,147)$. Without suggesting that a simple and direct correlation exists between peripheral sensory input and behavioral output, we may expect sensory variation to play a role in the behavioral responses to infochemicals. However, this area is virtually unstudied. Perhaps chemoreceptors in predators are influenced by feeding history, as was found in other insects such as locusts (e.g. 1, 147). This influence could be the mechanism behind the above-mentioned differential responses to volatile kairomones by predatory mites. The literature contains a single study on variation in chemosensory sensitivity for parasitoids. In the parasitoid Leptopilina heterotoma, changes in the behavioral responses to odors as a result of associative learning are correlated with changes in sensitivity of the olfactory receptor neurones, suggesting that associative learning in these insects need not be restricted to brain processes (175).

PHYSIOLOGICAL STATE AND LEARNING A recent study showed that physiological state can determine what learned information is used in subsequent foraging (79). However, little is known about the effect of egg-load or hunger on learning processes. It would be interesting to investigate if the propensity to learn or the rate of learning is higher under high egg-load or hunger (i.e. low selectivity) conditions. Vet et al (177) hypothesized that in associative learning the strength of the response to the reinforcing stimulus determines the effect of the reinforcement. If the response to the reinforcer itself is variable to some extent, and higher under low selectivity conditions, a stronger learning effect under such conditions is expected. 


\section{INTRASPECIFIC VARIATION IN SOURCE}

Infochemicals are produced by living organisms. Members of a species producing them differ in their genetic background and environment. Therefore, we can expect genetic factors and phenotypic plasticity to generate variation in the quantity and quality of infochemical production. This variation adds to the complexity of the environment in which the natural enemy operates.

We realize that genetic and nongenetic sources of variation cannot be considered as discrete independent categories because phenotypic plasticity may have a genetic basis $(143,150,181)$. However for reasons of clarity, they are discussed below as separate entities.

\section{Genetic Variation}

Studies on genetic variation in infochemical production by herbivores are rare (but for pheromones, see 82). Only one study has investigated the effect of genetic variation in herbivore kairomone production on responses of natural enemies. In this case, predators of bark beetles distinguish between aggregation pheromones of different geographic strains of their prey (75). Such allopatric differences may not be relevant for individual natural enemies, but they can be expected to affect the evolution of responses to infochemicals at the population level.

Genetic variability in production of plant volatiles is more frequently reported (e.g. 20,41), and this variability is known to affect plant selection by insects (e.g. 53). Several examples show natural enemies distinguishing between odors from different plant cultivars $(35,167)$, even from closely related ones $(39,40)$. Glanded and glandless cotton cultivars that are otherwise genetically similar differ in the production of synomones that attract the parasitoid Campoletis sonorensis; glanded cultivars produced approximately 100 times more synomone than nonglanded cultivars $(39,40)$. Plant cultivars differ in production of spider mite-induced synomones that attract predatory mites $(31,156)$. How much of such variation is a natural enemy likely to encounter under more natural conditions? Empirical evidence to answer this question is lacking. In a theoretical paper, Sabelis \& De Jong (140) question whether all individual plants should attract natural enemies, and approach variation in synomone production from the plant's perspective in a functional way. They state that the evolution of the indirect defense strategy of natural enemy attraction through production of synomones is not a self-explanatory process. Costs are involved in the production of infochemicals, but these costs may be circumvented by relying on synomone production by conspecific neighbors. They conclude that a polymorphic evolutionary stable strategy [ESS (93)] of synomone production may be expected under a wide range of conditions (140). This conclusion should incite experimental studies on the 


\section{VET \& DICKE}

existence and importance of such variation under natural conditions and on how foraging natural enemies deal with it.

\section{Nongenetic Variation}

Nongenetic variation in infochemical production by herbivores is often provoked by plants. Pheromone production by herbivores, for example, can be induced by the presence of specific host plant volatiles indicative of a suitable habitat for reproduction $(57,95,129)$, and can also be affected by the plant genotype on which the adult herbivore feeds (16). How this variation in pheromone production affects foraging by natural enemies that employ these infochemicals in herbivore location remains to be investigated. Not only can plants influence pheromone production, they can also affect pheromone distribution: pheromones can adsorb to plant foliage $(109,194)$. Noldus et al (109) show that diurnal Trichogramma egg parasitoids use plant-adhered sex pheromones of their nocturnal host to locate a habitat with reproducing moths where host eggs can be expected.

Natural enemies that use waste products of herbivores, such as feces, are confronted with variation in kairomonal activity due to their victim's diet. Parasitoids may respond differently to hosts and their products when hosts are fed on different diets $(84,107,136,142,169)$. Perhaps this way natural enemies assess plant-related herbivore suitability.

Furthermore, volatiles produced through the interaction of a herbivore and its host plant may vary with herbivore species, plant species and plant variety, and most likely plant condition. We discussed earlier the implication of this variation for natural enemies (see sections on information from plants and on learning). Volatiles released by intact plants are known to vary with plant condition (188) and responses of natural enemies are affected by this variation $(103,154)$.

Above we discussed how plants can influence the emission of infochemicals in herbivores. They can also affect the emission of infochemicals by other plants. Several years of silence and skepticism followed the initial data on talking trees $(4,131)$ and the criticism of the methodology used (43), but new work has shown that chemicals of herbivore-damaged plants can induce defense actions in uninfested plants that are exposed to these infochemicals. This defense may affect herbivores indirectly through attraction of their natural enemies $(14,31,155)$, which implies that the odor plume resulting from herbivore damage may have larger dimensions than generally thought. This larger size increases the detectability of the information.

We have mentioned several factors that create variation in infochemical production and distribution. The degree of this variation may strongly differ between plant-herbivore systems. The foraging behavior of natural enemies is expected to have evolved to cope with this variation through a selective use of 
infochemicals from different trophic levels and through different degrees of behavioral plasticity.

\section{DIETARY SPECIALIZATION AND INFOCHEMICAL USE}

The animal's degree of dietary specialization is an important characteristic frequently used in comparative ecological and evolutionary studies. This concept has also been applied to natural enemies (e.g. 145, 177 and references therein), although knowledge on herbivore range is generally extremely sparse and difficult to estimate (3). Dietary specialization of natural enemies can be assigned to both the herbivore and plant level, which has important implications for the way infochemicals are used.

The observational-comparative method, which reveals correlations between species characteristics and ecological factors indicative of adaptation, can be an important tool for evolutionary biologists $(94,144)$; ecological entomologists have successfully applied it $(137,158,166,179)$. The comparative method can be used in addition to the experimental approach, which is not always applicable. In the following discussion, we correlate the dietary specialization of natural enemies with the way in which they employ infochemicals and so generate some testable general hypotheses.

\section{Dietary Specialization in Parasitoids vs Predators}

Although foraging theory often lumps predators and parasitoids together, their degree of dietary specialization differs essentially in several ways. Consequently, so will their use of infochemicals. Compared to predators, parasitoids are highly specialized at the herbivore level because of their intimate physiological dependence on the host for the development of their offspring. Parasitoids are even more specialized as the use of a host species is usually restricted to a specific developmental stage. The close parasitoid-host relationship is probably most clearly expressed in the intriguing phenomenon of host regulation: parasitoids have evolved sophisticated ways to manipulate the physiology and morphology (reviewed in 76, 187) and even behavior (13) of their host to their own advantage.

Parasitoids have to be highly selective in their choice of hosts for several other reasons. First, every parasitized host potentially yields one or more offspring. For predators the ratio of offspring production per individual prey is much lower. Therefore, the value of an individual herbivore is higher for parasitoids than for predators. Also, hosts, in contrast to prey, can be encountered more than once and superparasitization can often be maladaptive.

Foraging for herbivores involves searching and handling. To maximize reproductive success, overall attack rate with herbivores should be maximized (87). Attack rate is inversely related to both searching time and handling time. 


\section{VET \& DICKE}

Therefore, a reduction in either time component can lead to an increase in attack rate. Specialists, being more selective, use relatively more time for searching than generalists, handling time considered equal. The use of infochemicals can reduce the time needed for searching. Thus, specialists benefit more from a reduction in search time through an effective use of infochemicals than generalists.

How do parasitoids and predators compare in this respect? Compared with search time, handling time in predators is relatively long as it involves not only catching and consuming prey, but also digesting it, and attack rate is often more likely constrained by gut emptying than by search time $(101,138)$. Sabelis (138) suggested that the speed of gut emptying is under more severe selection for increasing reproductive success in predatory mites than the rate of prey encounter. In such cases, selection for improvement of infochemical use will be relatively weak. An analogous situation can be expected in egg-limited parasitoids, which need time to develop eggs, as compared with species that have their eggs available upon eclosion and are time-limited. We expect the latter to benefit more from a reduction in search time.

KAIROMONE USE BY PARASITOIDS VS PREDATORS Hence, parasitoids and predators are skewed to different ends of a continuum from specialist to generalist natural enemies. We hypothesize that the use of kairomones is transposed on this specialist-generalist continuum: from intense and specific through weak and nonspecific to an absence of kairomone use. Nonspecific cues may be reliable for generalists, but only specific information is reliable for specialists. This can be illustrated by several examples. The parasitoid Microplitis croceipes resides on one end of the continuum. Specialized on Heliothis species, it utilizes host-produced kairomones from a variety of sources, such as frass, hemolymph, and salivary secretion (71). Farther along the continuum are generalist parasitoids such as Aphaereta minuta, a larval parasitoid of many fly species. This parasitoid locates the host's habitat through the odor of decaying material (173). Upon arrival, it does not use any host-derived chemical information but attacks any larvae it locates through vibrotaxis, which are practically always dipterans in such substrates (L. E. M. Vet, unpublished data). Vibration is a highly detectable cue that, although very general, is reliable enough for this polyphagous parasitoid.

At the other end of the continuum are generalist predators such as formicine ants. These ants, which eat virtually any insect larva encountered, do not use prey-derived chemicals during foraging (e.g. 22, 42). In fact, no evidence indicates that polyphagous ants use kairomones, even though the chemical ecology of these predators is extremely well studied $(12,61)$. Strikingly, and in accordance with our presumption, the only example of kairomone use by an ant species refers to one that specializes on a particular prey: the termite- 
feeding ant Megaponera foetens, which exploits termite odors as kairomones (12). Other predators known to employ kairomones are also species with a limited prey range, such as coleopteran predators of bark beetles (e.g. 55) and phytoseiid mites feeding on herbivorous mites (31). Some phytoseiid species resemble parasitoids not only in their relatively restricted diet, but also in their high ratio of food to offspring conversion: up to $70 \%$ of the ingested food is transformed into eggs by Phytoseiulus persimilis (138).

\section{Dietary Specialization and Infochemicals in a Tritrophic Context}

The degree of specialization at a particular trophic level sets the degree of specificity of the information needed for successful foraging. For example, if natural enemies attack a wide variety of herbivores, even those belonging to different taxa, information on herbivore identity is relatively unimportant (e.g. the absence of infochemical use by ants, as discussed above). If, on the other hand, all victims predictably occur on the same plant species, information from the plant may become relatively very important.

Dietary specialization can be assigned to both the herbivore and plant level, but frustratingly little is actually known of the herbivore and plant range used by natural enemies. This assessment has many complications. It is easy to investigate the parasitoids of a particular host, but very difficult to discover all the hosts of a particular parasitoid (3). It is even more difficult to determine prey range for predators, as the prey eaten under natural conditions can only be determined by gut analyses or direct observations. Problems with establishing the plant range used are even greater. Even if the exact host-plant range of a herbivore is known, we cannot implicitly assume this is the host-plant range of its natural enemy. Several reports tell of herbivores being attacked while on one food plant but not on another $(183,184)$. More importantly, one must realize that specialization may be an attribute of a population (e.g. through local adaptation) rather than an attribute of a species throughout its geographic range (44).

This lack of ecological knowledge hinders the possibility of empirically correlating diet breadth with the way infochemicals are used. Here, we hypothesize on the evolution of infochemical use in a tritrophic context to guide future research. Figure 3 illustrates the different ecological settings used in this reasoning and depicts the diet breadth of a natural enemy species. We now discuss infochemical employment in relation to the diet breadth of the natural enemy according to the four groupings A-D given in Figure 3.

(A) SPECIALISTS AT HERBIVORE AND PLANT LEVEL When herbivore and plant range are very restricted, strong congenitally fixed responses to both kairomones and herbivore-induced synomones are expected. For natural 


\section{VET \& DICKE}

ecological context
造

1 plant

response by
natural enemy
A

B

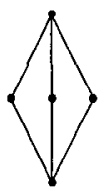

strong fixed
response to

response to
$\mathrm{X}, \mathrm{S}$ and HIS component
$\mathrm{C}$

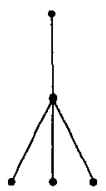

strong fixed response to $K$

learning of

$S$ and $H I S$
$\mathrm{D}$

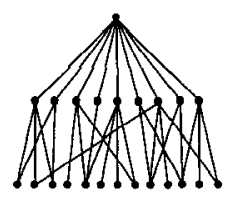

mo allelochemicals used

K-specifics

strong response

to $S$ and $H I S$

Figure 3 Dietary specialization and infochemical use in natural enemy species in a tritrophic context. Abbreviations are: K, kairomone; S, synomone; HIS, herbivore-induced synomone. Dots indicate different species.

enemies that attack nonfeeding herbivore stages, herbivore-induced synomones are not available. The importance of noninduced synomones depends on the probability of the herbivore's presence on its food plant. When this probability is very high, a solution to the reliability-detectability problem is to have strong congenitally fixed responses to both herbivore-induced and noninduced synomones.

(B) GENERALISTS AT HERBIVORE LEVEL AND SPECIALISTS AT PLANT LEVEL When, compared to situation $A$, the number of different herbivore species attacked is larger, natural enemies may be physiologically constrained from having congenitally fixed responses to kairomones from each specific herbivore. Instead, they may respond to general components present in all herbivore species (e.g. 58) and distinguish between different species through characteristic quantitative differences of each component of the kairomone mixture (106) and, perhaps, learn additional characteristics upon encountering the herbivores. Research has shown that in the Drosophila spp. parasitoid Asobara tabida, for example, females can learn to distinguish between kairomones of two related host species (166). If the presence of the different herbivore species is closely associated in time and space, natural enemies may restrict their responses to the kairomones of just one or a few herbivore species (60). Because of the basic influence of the plant on the composition of herbivore-induced synomones, relatively little variation in the composition of these chemicals is expected in situation B (156), which would favor congenitally fixed responses. 
(c) SPECIALISTS AT THE HERBIVORE LEVEL AND GENERALISTS AT THE PLANT LEVEL If, compared to A, the degree of polyphagy of the herbivore increases, herbivore-derived information becomes very important relative to plant-derived information. Strong congenitally fixed responses to kairomones are expected. Some congenitally fixed responses to volatiles from the most important host plant (i.e. in an evolutionary sense) may occur (e.g. 72) or responses may be elicited by a component that all host plants have in common (90). However in situation C, synomones are usually learned $(35,37,80$, 199).

If the herbivore species generally occurs on many plant species simultaneously, it may not be possible or adaptive to use plant information. This may be the case for Encarsia formosa, a parasitoid of the highly polyphagous whitefly Trialeurodes vaporariorum (110).

In situation $\mathrm{C}$, herbivore-induced synomones are expected to vary with plant species $(31,156)$, the degree of which depends on the relatedness of the plant species. Therefore, responses to these infochemicals are expected to be less fixed than in situation $\mathrm{B}$, and learning is expected to be more important.

(D) EXTREME GENERALISM AT BOTH LEVELS With an increase of diet breadth at both trophic levels, the adaptiveness of volatile allelochemical use will decrease. The great diversity of chemical information generates a physiological constraint on sensory processing and common chemical components will be very limited. For the individual, learning to forage for a subset of herbivores and plants is a solution when their distributions are clustered in time and space. If clustering is absent, such specialization may actually reduce encounter rates below that achieved with random search and hence may not be adaptive. For example, generalist ants do not use allelochemicals in foraging behavior (12). Temporary specialization does occur in these ants, but not through the learning of allelochemicals but by using trail pheromones and landmark learning $(12,22,42)$.

INTERMEDIATES Situations A, B, C, and D can be considered as extremes, and the ecological setting of many natural enemy species will be intermediate. Many natural enemies attack a few herbivore species, each feeding on a few plant species. The way these species use infochemicals will depend on the relative importance of the diet breadth at each trophic level. An example of such a system, verging on situation $\mathrm{C}$, is that of Leptopilina heterotoma, a larval parasitoid of closely related drosophilid species. This parasitoid attacks its hosts in a variety of decaying materials such as fermenting fruits, rotting plant material, or mushrooms. Although naive wasps show some responses to odors from the host microhabitats, these responses are heavily subject to modification by learning $(119,174,176,178)$. 


\section{Dietary Specialization and Enemy-Free Space}

In the previous section, we compared natural enemy species within different ecological settings and suggested that diet breadth is an important determinant of the way infochemicals are used. We considered the way infochemicals are used as an adaptation to the ecological setting. Alternatively, one could consider diet breadth as the result of an existing use of infochemicals (77, 184). However, in the real world both diet breadth and infochemical use are subject to evolutionary change and so these considerations should be regarded as complementary rather than antagonistic. Plant selection by natural enemies may affect herbivore host-plant selection and niche partitioning $(68,77,126$, 185). Also, as some host plants are not attractive or are less attractive to the natural enemies, these plants may provide an enemy-free space for herbivores. In other words, herbivores may avoid their enemies through plant selection $(9,69$; but see 51). Our ideas on infochemical use can refine this view. The more important plant odors are for the natural enemy, the more likely herbivores can successfully avoid their attackers. However, in several cases the plant odors used are induced by and specific for the herbivore, and successful escape may be less likely than generally assumed. Therefore, successful avoidance depends on the likelihood that natural enemies will not respond to the herbivore-specific plant odors emitted by the newly selected host plant species. Important aspects are $(a)$ chemical relatedness of the induced plant odors of the old and new plant species, which ultimately depends on the relatedness of the two plant species, and $(b)$ the degree of plasticity of the natural enemy's response. We hypothesize that learning of plant information by natural enemies constrains the successful shift of a herbivore to a new plant species. Therefore, avoidance success strongly depends on the ecological setting as expressed in Figure 3. The chances for escape are best in situations $\mathrm{A}$ and $\mathrm{B}$, in which plant information is highly specific and responses to it are least plastic, and worst in situation $\mathrm{C}$, in which natural enemies learn plant components to a high degree. Discussing avoidance possibilities in situation $\mathrm{D}$ is not relevant in this context, as allelochemicals play little or no role.

\section{INFOCHEMICALS AND PEST MANAGEMENT}

Ever since the first discovery of infochemical use by natural enemies in the early 1970 s, investigators have speculated on possibilities for applying these infochemicals in pest management (e.g. 31, 50, 54, 78, 85, 108, 111, 123, 134). Similarly, the discovery of learning in parasitoids has provoked thoughts on improvement of natural enemy efficiency through behavioral manipulation (e.g. 50, 78, 81, 85, 119, 176, 186, 199). However, fundamental research on both the behavioral mechanisms underlying in- 
fochemical utilization and the ecological context within which infochemicals and learning are employed has lagged behind. As a consequence, application has remained in its infancy for 20 years.

This review approaches infochemical use from an ecological point of view. Does this change our ideas on possibilities for application? We have emphasized that the way infochemicals are used ultimately depends on several ecological characteristics such as diet breadth at different trophic levels, stage of herbivore attacked, and predictability of herbivore presence in time and space. The resulting variation in infochemical use--both within and between species - can be utilized in pest management in two ways: manipulation of the response by the natural enemy or manipulation of the source of the infochemical.

\section{Manipulating Responses of Natural Enemies}

Interspecific differences in the ability to use infochemicals can provide a basis for selecting the most suitable species of natural enemies for biological control of a particular herbivore $(67,108,115)$, perhaps even for control of a herbivore in a particular crop.

The possibility of selecting natural enemy strains has been apprehended considerably less. Strains that have evolved in different ecological settings may vary in traits that are considered significant for successful performance, such as climatic tolerance and evasion of host-immunity response $(34,97$, 116). Similarly, strains may differ in their infochemical use. Whether these latter differences are applicable has only recently been questioned $(108,116)$.

Variation within the individual may also offer potentials for application. An obvious, but as yet unconsidered possibility is to optimize synchronization of release of natural enemies with the physiological state in which they are most responsive. Another more frequently suggested application is to improve the natural enemy's foraging behavior through learning. One way is to enhance the natural enemy's responses to target stimuli prior to its release $(50,78,81$, $85,119,176)$. However, manipulation through learning can only be achieved within certain limits and may be restricted to certain species. As argued above (see the section on dietary specialization and infochemical use), the need for behavioral plasticity gained through learning may differ considerably between species that have evolved in different ecological settings. Assuming that this differential need for learning has shaped the learning ability of a species (but see 117), we may find that modifying the behavior is not feasible in certain natural enemy species. Application of learning is expected to be most feasible for natural enemy species that have evolved in ecological setting $C$ illustrated in Figure 3, i.e. natural enemies that are specialized at the herbivore level and are generalists at the plant level. Independent of this ecological setting, learning of plant volatiles is generally more likely than learning of herbivore- 
derived cues. Therefore, application of learning should aim at manipulating the natural enemy's response to plant volatiles.

Plant volatiles are mainly used at the beginning of a foraging sequence during which the animal's area of search and thus its selection options are continuously reduced. Hence, modification of this initial foraging step through learning is most effective, as this application largely impacts the total foraging and herbivore selection process. Through an increased focus on crop volatiles, the tendency for released parasitoids to disperse can be reduced, which may be the most promising and realistic application of learning (176). Indeed, the limited field evidence on the effect of learning on foraging efficiency is for parasitoid species that verge on ecological setting $\mathrm{C}$ (Figure 3 ), in which responses to the first trophic level were modified by learning, dispersal was significantly reduced, and foraging efficiency increased (78, 119).

The selected natural enemy species or strain with its characteristic behavior and its potential for behavioral plasticity will also determine the success of other application possibilities, such as the manipulation of the infochemical source.

\section{Manipulating Sources of Infochemicals}

The most obvious and oldest idea for applying allelochemicals that mediate foraging behavior of natural enemies is to chemically identify the compounds, produce them, and disseminate them in the crop. This practice has been attempted without much success for two pest-parasitoid systems in which herbivore-derived kairomones that arrest parasitoids and stimulate local search behavior were applied to crops $(18,50)$. The main reason for the programs' failure is the incompatibility of the parasitoid behavior with a blanket spray distribution of the kairomones, while applying the kairomone in a more natural distribution, i.e. around herbivore egg batches, is both impracticable and illogical (50). Artificial dissemination of chemicals has not led to satisfactory results [although recent studies have produced information to the contrary (F. L. Wäckers \& W. J. Lewis, in preparation)], so the focus has shifted towards manipulation of the natural source of infochemicals. Manipulation of infochemical production by the pest population is hardly feasible, if not impossible, but manipulating the infochemical production by the crop has potential. Variation in production of volatiles by plants may be successfully employed to select plant cultivars that enhance foraging efficiency of natural enemies $(113,199)$. Especially promising is the use of cultivars with an increased production of herbivore-induced synomones at damaged sites. As these cultivars merely have an increased natural production of infochemicals, which are distributed in a natural pattern, problems like those encountered in applying synthetic chemicals are avoided (31). However, until 
the effect of elevated levels of herbivore-induced synomones on natural enemy searching behavior has been studied under field conditions, optimism remains premature. The search-time allocation of natural enemies may well change through increased aggregation at infested sites. In parasitoids this change could, for example, lead to undesirable levels of superparasitism and ineffective dispersion patterns.

Current plant breeding practices do not consider effects of plants on the third trophic level. This fact is unfortunate as an increase in natural enemy effectiveness could alleviate pest problems when used in concert with plant resistance $(11,170)$. The desired cultivars could possibly be developed through genetic engineering of crops, in addition to conventional plant breeding. This technique to achieve insect control is still in its infancy, judging from the 9-page, 20-reference paper on this subject in the Annual Review of Entomology in 1989 (96). The technique has been limited to effects on the pest insect directly, such as the production of insecticidal or antifeedant proteins in plants. As with conventional plant breeding, incorporation of effects on natural enemies would be desirable.

MONOCULTURES VS POLYCULTURES Implicitly we have considered infochemicals in agricultural systems where plants are grown in monocultures. Are responses of natural enemies to infochemicals affected by agricultural diversification? Polyculture systems are considered to reduce pest outbreaks (reviewed in 113) through their effect on the movement and reproductive behavior of pest insects (resource concentration hypothesis) and alternatively or additionally through an enhancement of populations of their natural enemies by providing them alternative food and shelter (enemies hypothesis). The presence of other nonhost plants hampers herbivore finding of their host plant, e.g. through masking effects, particularly in specialist herbivore species (98). We agree with Sheehan (145) that the enemies hypothesis as presently formulated, i.e. more abundant and effective natural enemies through alternative food sources, is too simplistic and that aspects of natural enemy searching behavior should also be considered for specialists and generalists comparatively. Here we question whether the effect of masking on the responses to plant infochemicals by natural enemies [which has incidentally been reported (102)] is of similar importance for plant specialists and plant generalists. Plant specialists show congenitally fixed responses to plant cues, while plant generalists, especially those that are specialists at the herbivore level, learn to respond to plant volatiles and to other environmental cues that are associated with herbivore presence (e.g. 80, 176, 192, 195, 196). Such environmental cues could actually involve cues from intercropped plants that are closely and predictably associated with the plants that accommodate their victims. Through this plasticity, the plant generalist can 


\section{VET \& DICKE}

create a complex search image (both visual and olfactory) of the microhabitat of the herbivore, whether this habitat is a mono- or a polyculture. The extent to which agricultural diversification affects the efficiency of a natural enemy species may therefore be ultimately determined by the enemies' behavioral plasticity and learning ability. Differences in these characteristics between natural enemy species may explain the unpredictable effect of multiple cropping on pest reduction (e.g. 132).

We could expand this reasoning to a comparison of herbivores and their natural enemies. Compared to herbivores, natural enemies as a whole can be considered more generalistic at the plant level because they generally attack at least a few herbivore species, each with their own host-plant range. Therefore, analogous to the arguments used for specialist and generalist herbivores (98), masking is considered less important for natural enemies than for herbivores, and the searching behavior of natural enemies is therefore less likely to be negatively influenced by associated plants as compared to that of herbivores (52). Additionally, the arguments on differences in learning between specialists and generalists support this notion. So, although the pestreduction effect of multiple cropping remains unpredictable, in general positive results are expected because of the more likely disturbance effect on foraging by herbivores than on foraging by their natural enemies.

\section{CONCLUDING REMARKS}

Despite the considerable amount of research on the use of infochemicals by natural enemies, the understanding of its evolution is limited: very few investigators go beyond a mechanistic approach. Through a lack of testable hypotheses, 20 years of research on a limited number of species has been conducted rather haphazardly. Moreover, the ecological information on the species studied is generally insufficient. Yet this information provides us with the framework for real-world hypotheses about behavioral adaptations. Comparative studies, both inter- and intraspecific, are essential. Major questions are (a) how foraging natural enemies deal with the reliability-detectability problem of infochemical use, $(b)$ how experience and physiological state influence the way infochemicals are used, and $(c)$ to what extent infochemical use is shaped by dietary specialization.

To elucidate the adaptiveness of infochemical use, the relation between fitness and variation in infochemical use should be determined. This will require research on the genetics underlying the behavioral responses. Insight into the genetic basis and genetic variability is elementary to an understanding of the evolution of the use of chemical information. Developing research on infochemicals along these lines will greatly add to the excitement of chemical ecology. 


\section{ACKNOWLEDGMENTS}

We thank J. Brodeur, J. C. Van Lenteren, H. P. Liepman, E. Van der Meijden, G. A. Pak, D. R. Papaj, P. W. Price, M. B. Sokolowski, T. C. J. Turlings, J. K. Waage, and F. L. Wäckers for their valuable comments on the manuscript. Discussion with F. Wäckers inspired the reliability-detectability concept. J. Roland provided us with information on tachinid parasitoids.

\section{Literature Cited}

1. Abisgold, J. D., Simpson, S. J. 1988. The effect of dietary protein levels and haemolymph composition on the sensitivity of the maxillary palp chemoreceptors of locusts. J. Exp. Biol. 135:215-29

2. Aldrich, J. R., Lusby, W. R., Koschansky, J. P. 1986. Identification of a new predaceous stink bug pheromone and its attractiveness to the eastern yellowjacket. Experientia 42:583-85

3. Askew, R. R., Shaw, M. R. 1986. Parasitoid communities: their size, structure and development. See Ref. 191, pp. 225-64

4. Baldwin, I. T., Schultz, J. C. 1983. Rapid changes in tree leaf chemistry induced by damage: evidence for communication between plants. Science 221:277-79

5. Barbosa, P. 1988. Natural enemies and herbivore-plant interactions: influence of plant allelochemicals and host specificity. See Ref. 6, pp. 201-229

6. Barbosa, P., Letourneau, D. K., eds. 1988. Novel Aspects of Insect-Plant Interactions. New York: Wiley. 362 pp.

7. Bell, W. J. 1990. Searching behavior patterns in insects. Annu. Rev. Entomol. 35:447-67

8. Bell, W. J., Cardé, R. T., eds. 1984. Chemical Ecology of Insects. London: Chapman and Hall. 512 pp.

9. Bernays, E., Graham, M. 1988. On the evolution of host specifity in phytophagous arthropods. Ecology 69:886-92

10. Blaney, W. M., Schoonhoven, L. M., Simmonds, M. S. J. 1986. Sensitivity variations in insect chemoreceptors: a teview. Experientia 42:13-19

11. Boethel, D. J., Eikenbary, R. D., eds. 1986. Interactions of Plant Resistance and Parasitoids and Predators of $I n$ sects. Chichester: Ellis Horwood. 224 pp.

12. Bradshaw, J. W. S., Howse, P. E. 1984. Sociochemicals of ants. See Ref. 8, pp. $429-73$
13. Brodeur, J., McNeil, J. N. 1989. Seasonal microhabitat selection by an endoparasitoid through adaptive modification of host behavior. Science 244:22628

14. Bruin, J., Dicke, M., Sabelis, M. W. 1991. Plants are better protected against spider mites after exposure to volatiles from infested conspecifics. Experientia. In press

15. Carlin, N. F., Hölldobler, B. 1983. Nestmate and kin recognition in interspecific mixed colonies of ants. Science 222:1027-29

16. Chang, J. F., Benedict, J. H., Payne, T, L., Camp, B. J. 1988. Pheromone production of the boll weevil in response to seven cotton genotypes grown in two environments. Environ. Entomol. 17: $921-25$

17. Charnov, E. L., Skinner, S. W. 1988. Clutch size in parasitoids: the egg production rate as a constraint. Evol. Ecol. 2:167-74

18. Chiri, A. A., Legner, E. F. 1983. Field applications of host-searching kairomones to enhance parasitization of the pink bollworm (Lepidoptera: Gelechiidae). J. Econ. Entomol. 76:254-55

19. Chiri, A. A., Legner, E. F. 1986. Response of three Chelonus (Hymenoptera: Braconidae) species to kairomones in scales of six Lepidoptera. Can. Entomol. 118:329-33

20. Cole, R. A., Phelphs, K. 1979. Use of canonical variate analysis in the differentiation of Swede cultivars by gasliquid chromatography of volatile hydrolysis products. J. Sci. Food Agric. 30:669-76

21. Collins, M. D., Ward, S. A., Dixon, A. F. G. 1981. Handling time and the functional response of Aphelinus thomsoni, a predator and parasite of the aphid Drepanosiphum platanoidis. J. Anim. Ecol. 50:479-87

22. Cosens, D., Toussaint, N. 1985. An experimental study of the foraging strategy of the wood ant Formica aquilonia. Anim. Behav. 33:541-52 
23. Curio, E. 1976. The Ethology of Predation. New York: Springer Verlag. 250 pp.

24. Curry, G. L., DeMichele, D. W. 1977. Stochastic analysis for the description and synthesis of predator-prey systems. Can. Entomol. 109:1167-74

25. Dethier, V. G. 1976. The Hungry Fly: A Physiological Study of the Behavior Associated with Feeding. Cambridge, MA: Harvard Univ. Press. 489 pp.

26. Dicke, M. 1988. Microbial allelochemicals affecting the behavior of insects, mites, nematodes and protozoa in different trophic levels. See Ref. 6, pp. $125-63$

27. Dicke, M., De Jong, M., Alers, M. P. T., Stelder, F. C. T., Wunderink, R., Post, J. 1989. Quality control of massreared arthropods: Nutritional effects on performance of predatory mites. J. Appl. Entomol. 108:462-75

28. Dicke, M., Groeneveld, A. 1986. Hierarchical structure in kairomone preference of the predatory mite Amblyseius potentillae: dietary component indispensable for diapause induction affects prey location behaviour. Ecol. Entomol. 11:131-38

29. Dicke, M., Sabelis, M. W. 1988. Infochemical terminology: based on cost-benefit analysis rather than origin of compounds? Funct. Ecol. 2:13139

30. Dicke, M., Sabelis, M. W. 1989. Does it pay plants to advertize for body. guards? Towards a cost-benefit analysis of induced synomone production. In Causes and Consequences of Variation in Growth Rate and Productivity of Higher Plants, ed. H. Lambers, M. L. Cambridge, H. Konings, T. L. Pons, pp. 341-58. The Hague: SPB Academic

31. Dicke, M., Sabelis, M. W., Takabayashi, J., Bruin, J., Posthumus, M. A. 1990 . Plant strategies of manipulating predator-prey interactions through allelochemicals: prospects for application in pest control. J. Chem. Ecol. 16:3091-3118

32. Dicke, M., Van Beek, T. A., Posthumus, M. A., Ben Dom, N., Van Bokhoven, H., de Groot, Æ. 1990. Isolation and identification of volatile kairomone that affects acarine predatorprey interactions. Involvement of host plant in its production. J. Chem. Ecol. 16:381-96

33. Dicke, M., Van der Maas, K. J., Takabayashi, J., Vet, L. E. M. 1990. Learning affects response to volatile allelochemicals by predatory mites. Proc. Exp.
Appl. Entomol. Ned. Entomol. Ver. Amsterdam 1:31-37

34. Diehl, S. R., Bush, G. L. 1984. An evolutionary and applied perspective of insect biotypes. Annu. Rev. Entomol. 29:471-504

35. Ding, D., Swedenborg, P. D., Jones, R. L. 1989. Plant odor preferences and learning in Macrocentrus grandii (Hymenoptera: Braconidae), a larval parasitoid of the European corn borer, Ostrinia nubilalis (Lepidoptera: Pyralidae). J. Kans. Entomol. Soc. 62:164-76

36. Donaldson, J. A., Walter, G. H. 1988. Effects of egg availability and egg maturity on the ovipositional activity of the parasitic wasp, Coccophagus atratus. Physiol. Entomol. 13:407-17

37. Drost, Y. C., Lewis, W. J., Zanen, P. O., Keller, M. A. 1986. Beneficial arthropod behavior mediated by airborne semiochemicals. I. Flight behavior and influence of preflight handling of Microplitis croceipes (Cresson). J. Chem. Ecol. 12:1247-62

38. Eller, F. J., Tumlinson, J. H., Lewis, W. J. 1988. Beneficial arthropod behavior mediated by airborne semiochemicals. II. Olfactometric studies of host location by the parasitoid Microplitis croceipes (Cresson) (Hymenoptera: Braconidae). J. Chem. Ecol. 14:42534

39. Elzen, G. W., Williams, H. J., Bell, A. A., Stipanovic, R. D., Vinson, S. B. 1985. Quantification of volatile terpenes of glanded and glandless Gossypium hirsutum L. cultivars and lines by gas chromatography. J. Agric. Food Chem. 33:1079-82

40. Elzen, G. W., Williams, H. J., Vinson, S. B. 1986. Wind tunnel flight responses by hymenopterous parasitoid Campoletis sonorensis to cotton cultivars and lines. Entomol. Exp. Appl. 42:285-89

41. Fenwick, G. R., Heany R. K., Mullin, W. J. 1983. Glucosinolates and their breakdown products in food and food plants. CRC Crit. Rev. Food Sci. Nutr. 18(2):123-201

42. Fourcassie, V., Beugnon, G. 1988. How do red wood ants orient when foraging in a three dimensional system? I. Laboratory experiments. Insectes Soc. 35:92-105

43. Fowler, S. V., Lawton, J. H. 1985. Rapidly induced defenses and talking trees: the devil's advocate position. Am. Nat. 126:181-95

44. Fox, L. R., Morrow, P. A. 1981. Specialization: species property or local phenomenon? Science 211:887-93

45. Gardner, S. M., Van Lenteren, J. C. 
1986. Characterisation of the arrestment responses of Trichogramma evanescens. Oecologia 68:265-70

46. Geissler, T. G., Rollo, C. D. 1988. The influence of nutritional history on the response to novel food by the cockroach, Periplaneta americana (L.). Anim. Behav. 35:1905-7

47. Graf, S. A., Sokolowski, M. B. 1989. The rover/sitter Drosophila foraging polymorphism as a function of larval development, food patch quality and starvation. J. Insect Behav. 2:301-13

48. Greany, P. D., Hagen, K. S. 1981. Prey selection. See Ref. 111, pp. 121-35

49. Greenstone, M. H. 1979. Spider feeding behaviour optimises dietary essential amino acid composition. Nature 282: 501-3

50. Gross, H. R. 1981. Employment of kairomones in the management of parasitoids. See Ref. 111, pp, 137-50

51. Gross, P., Price, P. W. 1988. Plant influences on parasitism of two leafminers: a test of enemy free space. Ecology 69:1506-16

52. Guerin, P. M. 1987. Semiochemicals in insect-plant relations: Their application as agents for masking crop colonization by pests. In Integrated Pest Management: Quo Vadis?, ed. V. Delucchi, pp. 257-74. Geneva: Parasitis. $411 \mathrm{pp}$.

53. Guerin, P. M., Städler, E. 1984. Carrot fly cultivar preferences: some influencing factors. Ecol. Entomol. 9:413-20

54. Hagen, K. S. 1986. Ecosystem analysis: Plant cultivars (HPR), entomophagous species and food supplements. See Ref. 11, pp. 151-197

55. Haynes, K. F., Birch, M. C. 1985 . The role of other pheromones, allomones and kairomones in the behavioral responses of insects. In Comprehensive Insect Physiology, Biochemistry and Pharmacology, ed. G. A. Kerkut, L. I. Gilben, 9:225-55. Oxford: Pergamon

56. Helle, W., Sabelis, M. W., eds. 1985. Spider Mites. Their Biology, Natural Enemies and Their Control, World Crop Pests Vol. 1B. Amsterdam: Elsevier. $458 \mathrm{pp}$.

57. Hendrikse, A., Vos-Bünnemeyer, E. 1987. Role of host-plant stimuli in sexual behaviour of small ermine moths (Yponomeuta). Ecol. Entomol. 12:36371

58. Henson, R. D., Vinson, S. B., Barfield, C. S. 1977. Ovipositional behavior of Bracon mellitor Say, a parasitoid of the boll weevil (Anthonomus grandis Boheman). III. Isolation and identification of natural releasers of ovipositor probing. J. Chem. Ecol. 3:151-58
59. Hérard, F., Keller, M. A., Lewis, W. J., Tumlinson, J. H. 1988. Beneficial arthropod behavior mediated by airborne semiochemicals. III. Influence of age and experience on flight chamber responses of Microplitis demolitor Wilkinson. J. Chem. Ecol. 14:1583-96

60. Heuer, H. G., Vité, J. P. 1984. Chalcogran: unique kairomone-governed predator-prey relations among ostomid and scolytid beetles. Naturwissenschaften 71:214

61. Hölldobler, B., Wilson, E. O. 1990. The Ants. Berlin: Springer Verlag. 732 pp.

62. Holling, C. S. 1966. The functional response of invertebrate predators to prey density. Mem. Entomol. Soc. Canada 48:1-86

63. Howard, R. W., Flinn, P. W. 1990. Larval trails of Cryptolestes ferrugineus (Coleoptera: Cucujidae) as kairomonal host-finding cues for the parasitoid Cephalonomia waterstoni (Hymenoptera: Bethylidae). Ann. Entomol. Soc. Am. 83:239-45

64. Isingrini, M., Lenoir, A., Jaisson, P. 1985. Preimaginal learning as a basis of colony-brood recognition in the ant Cataglyphis cursor. Proc. Natl. Acad. Sci. USA 82:8545-47

65. Iwasa, Y., Suzuki, Y., Matsuda, H. 1984. Theory of oviposition strategy of parasitoids. I. Effect of mortality and limited egg number. Theor. Pop. Biol. 26:205-27

66. Jaenike, J. 1985. Genetic and environmental determinants of food preference of Drosophila tripunctata. Evolution 39:362-69

67. Janssen, A., Hofker, C. D., Braun, A. R., Mesa, N., Sabelis, M. W., Bellotti, A. C. 1990. Preselecting predatory mites for biological control: the use of an olfactometer. Bull. Entomol. Res. 80: $177-81$

68. Jeffries, M. J., Lawton, J. H. 1984. Enemy free space and the structure of ecological communities. Biol. J. Linn. Soc. 23:269-86

69. Jermy, T. 1988. Can predation lead to narrow food specialization in phytophagous insects? Ecology 69:902-4

70. Deleted in proof

71. Jones, R. L., Lewis, W. J., Bowman, M. C., Beroza, M., Bierl, B. A. 1971. Host seeking stimulants for parasite of corn earworm: isolation, identification and synthesis. Science 173:842-43

72. Kaiser, L., Cardé, R. T. 1991. In-flight orientation to volatiles from the planthost complex in Cotesià rubecula (Hym.: Braconidae): increased sensitiv- 
ity through olfactory experience. Physiol. Entomol. In press

73. Kaiser, L., Pham-Delegue, M. H., Bakchine, E., Masson, C. 1989. Olfactory responses of Trichogramma maidis Pint. et Voeg.: Effects of chemical cues and behavioral plasticity. J. Insect Behav. 2:702-12

74. Klowden, M. J. 1986. Effects of sugar deprivation on the host-seeking behaviour of gravid Aedes aegypti mosquitoes. J. Insect Physiol. 32:479-83

75. Lanier, G. N., Birch, M. C., Schmitz, R. F., Furniss, M. M. 1972. Pheromones of Ips pini (Coleoptera: Scolytidae): variation in response among three populations. Can. Entomol. 104:1917 23

76. Lawrence, P. O., Vinson, S. B. 1990. Biochemistry, endocrinology and physiological ecology of insect host-parasite systems. Arch. Insect Biochem. Physiol. 13:1-265

77. Lawton, J. H. 1986. The effect of parasitoids on phytophagous insect communities. See Ref. 191, pp. 265-87

78. Lewis, W. J., Martin, W. R. 1990. Semiochemicals for use in biological control: status and future. J. Chem. Ecol. 16:3067-89

79. Lewis, W. J., Takasu, K. 1990. Use of learned odours by a parasitic wasp in accordance with host and food needs. Nature 348:635-36

80. Lewis, W. J., Tumlinson, J. H. 1988. Host detection by chemically mediated associative learning in a parasitic wasp. Nature 331:257-59

81. Lewis, W. J., Vet, L. E. M., Tumlinson, J. H., Van Lenteren, J. C., Papaj, D. R. 1990. Variation in parasitoid foraging behavior: Essential element of a sound biological control theory. Environ. Entomol. 19:1183-93

82. Lofstedt, C. 1990 . Population variation and genetic control of pheromone communication systems in moths. Entomol. Exp. Appl. 54:199-218

83. Loke, W. H., Ashley, T. R. 1984a. Behavioral and biological responses of Cotesia marginiventris to kairomones of the fall armyworm, Spodoptera frugiperda. J. Chem. Ecol. 10:521-29

84. Loke, W. H., Ashley, T. R. 1984 b. Sources of fall armyworm, Spodoptera frugiperda (Lepidoptera: Noctuidae), kairomones eliciting host-finding behavior in Cotesia (=Apanteles) marginiventris (Hymenoptera: Braconidae). $J$. Chem. Ecol. 10:1019-27

85. Loke, W. H., Ashley, T. R. 1984c. Potential use of kairomones for behavioral manipulation of Cotesia margi- niventris (Cresson). J. Chem. Ecol. 10:1377-84

86. Luck, R. F., Uygun, N. 1986. Host recognition and selection by Aphytis species: Response to California red, oleander, and cactus scale cover extracts. Entomol. Exp. Appl. 40:12936

87. MacArthur, R. H., Pianka, E. R. 1966. On optimal use of a patchy environment. Am. Nat. 916:603-9

88. Mackauer, M., Ehler, L. E., Roland, J., eds. 1990. Critical Issues in Biological Control. Andover: Intercept. $330 \mathrm{pp}$.

89. Mangel, M. 1989. Evolution of host selection in parasitoids. Does the state of the parasitoid matter? Am. Nat. 133: 688-705

90. Martin, W. R., Nordlund, D. A., Nettles, W. C. 1990. Response of parasitoid Eucelatoria bryani to selected plant material in an olfactometer. J. Chem. Ecol. 16:499-508

91. Masson, C., Mustaparta, H. 1990. Chemical information processing in the olfactory system of insects. Physiol. Rev. 70:199-245

92. Mauricio, R., Bowers, M. D. 1990. Do caterpillars disperse their damage?: Larval foraging behaviour of two specialist herbivores, Euphydras phaeton (Nymphalidae) and Pieris rapae (Pieridae). Ecol. Entomol. 15:153-61

93. Maynard Smith, J. 1974. The theory of games and the evolution of animal conflicts. J. Theor. Biol. 47:209-21

94. Mayr, E. 1982. The Growth of Biological Thought: Diversity, Evolution, and Inheritance. Cambridge: Harvard Univ. Press. 974 pp.

95. McNeil, J. N., Delisle, J. 1989. Are host plants important in pheromonemediated mating systems of Lepidoptera? Experientia 45:236-40

96. Meeusen, R. L., Warren, G. 1989. Insect control with genetically engineered crops. Annu. Rev. Entomol. 34:373-81

97. Messenger, P. S., Van den Bosch, R. 1971. The adaptability of introduced biological control agents. In Biological Control, ed. C. B. Huffaker, pp. 68-92. New York: Plenum. 511 pp.

98. Miller, J. R., Strickler, K. L. 1984. Finding and accepting host plants. See Ref. 8, pp. 127-57

99. Mitchell, W. C., Mau, F. L. 1971. Response of the female southern green stink bug and its parasite, Trichopoda pinnipes, to male stink bug pheromones. J. Econ. Entomol. 64:856-59

100. Mizell, R. F., Frazier, J. L., Nebeker, T. E. 1984. Response of the clerid predator Thanasimus dubius (F.) to bark bee- 
tle pheromones and tree volatiles in a wind tunnel. J. Chem. Ecol. 10:177-87

101. Mols, P. J. M. 1988. Simulation of hunger, feeding and egg production in the carabid beetle Pterostichus coerulescens L. (= Poecilus versicolor Sturm). Agric. Univ. Wageningen Pap. 88(3): 1-99

102. Monteith, L. G. 1960 . Influence of plants other than the food plants of their host on host-finding by tachinid parasites. Can. Entomol. 92:641-52

103. Monteith, L. G. 1964. Influence of the health of food plant of the host on hostfinding by tachinid parasites. Can. Entomol. 96:1477-82

104. Nealis, V. G. 1986. Responses to host kairomones and foraging behaviour of the insect parasite Cotesia rubecula (Hymenoptera: Braconidae). Can. J. Zool. 64:2393-98

105. Nealis, V. G. 1990 . Factors affecting the rate of attack by Cotesia rubecula (Hymenoptera: Braconidae). Ecol. Entomol. 15:163-68

106. Nemoto, T., Kuwahara, Y., Suzuki, T. 1987. Interspecific difference in Venturia kairomones in larval feces of four stored phycitid moths. Appl. Entomol. Zool. 22:553-59

107. Nettles, W. C. 1980. Adult Eucelatoria sp.: Response to volatiles from cotton and okra plants and from larvae of Heliothis virescens, Spodoptera eridania, and Estigmene acrea. Environ. Entomol. 9:759-63

108. Noldus, L. P. J. J. 1989. Semiochemicals, foraging behaviour and quality of entomophagous insects for biological control. J. Appl. Entomol. 108:425-51

109. Noldus, L. P. J. J., Potting, R. P. J., Barendregt, H. E. 1991. Moth sex pheromone adsorption to leaf surface: bridge in time for chemical spies. Physiol. Entomol. In press

110. Noldus, L. P. J. J., Van Lenteren, J. C. 1990. Host aggregation and parasitoid behaviour: biological control in a closed system. See Ref. 88, pp. 229-62

111. Nordlund, D. A., Jones, R. L., Lewis, W. J., eds. 1981. Semiochemicals, Their Role in Pest Control. New York: Wiley. 306 pp.

112. Nordlund, D. A., Lewis, W. J. 1976. Terminology of chemical releasing stimuli in intraspecific and interspecific interactions. J. Chem. Ecol. 2:211-20

113. Nordlund, D. A., Lewis, W. J., Altieri, M. A. 1988. Influences of plantproduced allelochemicals on the host/ prey selection behavior of entomophagous insects. See Ref. 6, pp. 65-90

114. Obrycki, J. J. 1986. The influence of foliar pubescence on entomophagous species. See Ref. 11, pp. 61-83

115. Pak, G. A., De Jong, E. J. 1987. Behavioural variations among strains of Trichogramma spp.: host recognition. Neth. J. Zool. 37:137-66

116. Pak, G. A., Kaskens, J. W. M., De Jong, E. J. 1990. Behavioural variation among strains of Trichogramma spp.: host-species selection. Entomol. Exp. Appl. 56:91-102

117. Papaj, D. R. 1986. Interpopulation differences in host preference and the evolution of learning in the butterfly Battus philenor. Evolution 40:518-30

117a. Papaj, D. R. 1992. Automatic behavior and the evolution of instinct: lessons from learning in parasitoids. In Insect Learning: Ecological and Evolutionary Perspectives, ed. D. R. Papaj, A. C. Lewis. New York: Chapman and Hall. In press

118. Papaj, D. R., Prokopy, R. J. 1989. Ecological and evolutionary aspects of learning in phytophagous insects. Annu. Rev. Entomol. 34:315-50

119. Papaj, D. R., Vet, L. E. M. 1990 . Odor learning and foraging success in the parasitoid Leptopilina heterotoma. J. Chem. Ecol. 16:3137-50

120. Deleted in proof

121. Payne, T. L., Dickens, J. C., Richerson, J. V. 1984. Insect predator-prey coevolution via enantiomeric specificity in a kairomone-pheromone system. $J$. Chem. Ecol, 10:487-92

122. Pospisil, J. 1958. Neketere problemy cichu u saprofilnich much (Some problems of the smell of the Saprophilic flies). Act. Soc. Entomol. Czech. 55: 316-33

123. Powell, W. 1986. Enhancing parasitoid activity in crops. See Ref. 191, pp. 319 40

124. Prévost, G., Lewis, W. J. 1990 . Genetic differences in the response of Microplitis croceipes to volatile semiochemicals. $J$. Insect Behav. 3:277-87

125. Price, P. W. 1981. Semiochemicals in evolutionary time. See Ref. 111, pp. 251-71

126. Price, P. W., Bouton, C. E., Gross, P., McPheron, B. A., Thompson, J. N., Weis, A. E. 1980. Interactions among three trophic levels: influence of plant interactions between insect herbivores and natural enemies. Annu. Rev. Ecol. Syst. 11:41-65

127. Prokopy, R. J., Webster, R. P. 1978. Oviposition-deterring pheromone of Rhagoletis pomonella: a kairomone for its parasitoid Opius lectus. J. Chem. Ecol. 4:481-94 
128. Putters, F. A., Van den Assem, J. 1988. The analysis of partial preferences in a parasitic wasp. Anim. Behav. 36:933-48

129. Raina, A. K. 1988. Selected factors influencing neurohormonal regulation of sex pheromone production in Heliothis species. J. Chem. Ecol. 14:2063-69

130. Rausher, M. D. 1985 . Variability for host preference in insect populations: mechanistic and evolutionary models. $J$. Insect Physiol. 31:873-89

131. Rhoades, D. F. 1985. Offensivedefensive interactions between herbivores and plants: their relevance in herbivore population dynamics and ecological theory. Am. Nat. 125:205-38

132. Risch, S. J., Andow, D. A., Altieri, M. A. 1983. Agroecosystem diversity and pest control: data, tentative conclusions, and new research directions. Environ. Entomol. 12:625-29

133. Roland, J. 1990. Parasitoid aggregation: Chemical ecology and population dynamics. See Ref. 88, pp. 185-211

134. Roland, J., Evans, W. G., Myers, J. H. 1989. Manipulation of oviposition patterns of the parasitoid Cyzenis albicans (Tachinidae) in the field using plant extracts. J. Insect Behav. 2:487-503

135. Roth, J. P., King, E. G., Hensley, S. D. 1982. Plant, host, and parasite interactions in the host selection sequence of the tachinid Lixophaga diatraeae. Environ. Entomol. 11:273-77

136. Roth, J. P., King, E. G., Thompson, A. C. 1978. Host location behavior by the tachinid Lixophaga diatraeae. Environ. Entomol. 7:794-98

137. Sabelis, M. W. 1985. Development. See Ref. 56, pp. 43-53

138. Sabelis, M. W. 1986. The functional response of predatory mites to the density of two-spotted spider mites. In Lecture Notes in the Dynamics of Physiologically Structured Populations, ed. J. A. J. Metz, O. Diekmann, Biomathematics 68:298-321. Berlin: Springer-Verlag. $511 \mathrm{pp}$.

139. Sabelis, M. W. 1990. How to analyse prey preference when prey density varies? A new method to discriminate between effects of gut fullness and prey type composition. Oecologia 82:289-98

140. Sabelis, M. W., De Jong, M. C. M. 1988. Should all plants recruit bodyguards? Conditions for a polymorphic ESS of synomone production in plants. Oikos 53:247-52

141. Sabelis, M. W., Dicke, M. 1985. Longrange dispersal and searching behaviour. See Ref. 56, pp. 141-60

142. Sauls, C. E., Nordlund, D. A., Lewis, W. J. 1979. Kairomones and their use for management of entomophagous insects. VIII. Effect of diet on the kairomonal activity of frass from Heliothis zea (Boddie) larvae for Microplitis croceipes (Cresson). J. Chem. Ecol. 5:363-69

143. Schlichting, C. D. 1986 . The evolution of phenotypic plasticity in plants. Annu. Rev. Ecol. Syst. 17:667-93

144. Schoener, T. W. 1974. Resource partitioning in ecological communities. Science 185:27-38

145. Sheehan, W. 1986. Response by specialist and generalist natural enemies to agroecosystem diversification: a selective revicw. Environ. Entomol. 15:45661

146. Sheehan, W., Shelton, A. M. 1989. The role of experience in plant foraging by the aphid parasitoid Diaeretiella rapae (Hymenoptera: Aphidiidae). J. Insect Behav. 2:743-59

147. Simpson, C. J., Simpson, C. L. 1990. The mechanisms of nutritional compensation by phytophagous insects. In Focus on Insect-Plant Relations, ed. E. A. Bernays, 2:111-60. New York: CRC Press

148. Singer, M. C. 1982. Quantification of host preference by manipulation of oviposition behavior in the butterfly Euphydryas editha. Oecologia 52:22429

149. Sokolowski, M. B. 1985. Ecology, genetics and behavior of Drosophila larval foraging and pupation behavior. $J$. Insect Physiol. 31:857-64

150. Steams, S. C. 1989. The evolutionary significance of phenotypic plasticity. BioScience 39:436-45

151. Stephens, D. W. 1990. Risk and incomplete information in behavioral ecology. In Risk and Uncertainty in Tribal and Peasant Economies, ed. E. Cashdan, pp. 19-46. Boulder, CO: Westview Press. 342 pp.

152. Strand, M. R., Vinson, S. B. 1982 . Behavioral response of the parasitoid $\mathrm{Car}$ diochiles nigriceps to a kairomone. Entomol. Exp. Appl. 31:308-15

153. Sugimoto, T., Shimono, Y., Hata, Y., Nakai, A., Yahara, M. 1988. Foraging for patchily-distributed leaf-miners by the parasitoid, Dapsilarthra rufiventris (Hymenoptera: Braconidae) III. Visual and acoustic cues to a close range patchlocation. Appl. Entomol. Zool. 23:11321

154. Takabayashi, J., Dicke, M., Kemerink, J., Veldhuizen, T. 1990. Environmental effects on production of plant synomone that attracts predatory mites. Symp. Biol. Hung. 39:541-42 
155. Takabayashi, J., Dicke, M., Posthumus, M. A. 1991. Induction of indirect defence against spider mites in uninfested Lima bean leaves. Phytochemistry 30:1459-62

156. Takabayashi, J., Dicke, M., Posthumus, M. A. 1991. Variation in composition of predator-attracting allelochemicals emitted by herbivore-infested plants: relative influence of plant and herbivore. Chemoecology 2:1-6

157. Thompson, M. S., Stinner, R. E. 1990. The scale response of Trichogramma (Hymenoptera: Trichogrammatidae): variation among species in host specificity and the effect of conditioning. Entomophaga 35:7-21

158. Thornhill, R. 1984. Scientific methodology in entomology. Fla. Entomol. 67: $74-96$

159. Tinbergen, N. 1951. The Study of Instinct. London: Oxford Univ. Press. 228 pp.

160. Turlings, T. C. J., Scheepmaker, J. W. A., Vet, L. E. M., Tumlinson, J. H., Lewis, W. J. 1990. How contact foraging experiences affect preferences for host-related odors in the larval parasitoid Cotesia marginiventris (Cresson) (Hymenoptera: Braconidae). J. Chem. Ecol. 16:1577-89

161. Turlings, T. C. J., Tumlinson, J. H., Eller, F. J., Lewis, W. J. 1991. Larvaldamaged plants: source of volatile synomones that guide the parasitoid Cotesia marginiventris to the micro-habitat of its hosts. Entomol. Exp. Appl. 58:75-82

162. Turlings, T. C. J., Tumlinson, J. H., Heath, R. R., Doolittle, R. E. 1991. Isolation and identification of allelochemicals that attract the larval parasitoid Cotesia marginiventris (Cresson) to the microhabitat of one of its hosts. $J$. Chem. Ecol. 17: In press

163. Turlings, T. C. J., Tumlinson, J. H., Lewis, W. J. 1990. Exploitation of herbivore-induced plant odors by hostseeking parasitic wasps. Science 250: $1251-53$

164. Turlings, T. C. J., Tumlinson, J. H., Lewis, W. J., Vet, L. E. M. 1989. Beneficial arthropod behavior mediated by airborne semiochcmicals. VIII. Learning of host-related odors induced by a brief contact experience with host by-products in Cotesia marginiventris (Cresson), a generalist larval parasitoid. J. Insect Behav. 2:217-25

165. Ullyett, G. C. 1953. Biomathematics and insect population problems. Entomol. Soc. South Afr. Mem. 2:1-89

166. Van Alphen, J. J. M., Vet, L. E. M. 1986. An evolutionary approach to host finding and selection. See Ref. 191, pp. 23-61

167. Van Emden, H. F. 1986. The interaction of plant resistance and natural enemies: effects on populations of sucking insects. See Ref. 11, pp. 138-50

168. Deleted in proof

169. Van Leerdam, M. B., Smith, J. W., Fuchs, T. W. 1985. Frass-mediated host-finding behavior of Cotesia flavipes, a braconid parasite of Diatraea saccharalis (Lepidoptera: Pyralidae). Ann. Entomol. Soc. Am. 78:647-50

170. Van Lenteren, J. C. 1991. Biological control in a tritrophic system approach. Proc. Int. Symp. Aphid-Plant Interactions: Populations to Molecules, ed. D. C. Peters, J. A. Webster, C. S. Chlouber, pp. 3-28. Stillwater, OK: Univ. of Oklahoma

171. Van Lenteren, J. C., De Ponti, O. M. B. 1991. Plant-leaf morphology, host-plant resistance and biological control. Symp. Biol. Hung. 39:365-86

172. Vet, L. E. M. 1983. Host-habitat location through olfactory cues by Leptopilina clavipes (Hartig) (Hym.: Eucoilidae) a parasitoid of fungivorous Drosophila: the influence of conditioning. Neth. $J$. Zool. 33:225-48

173. Vet, L. E. M. 1985. Olfactory microhabitat location in some eucoilid and alysiine species (Hymenoptera), larval parasitoid of Diptera. Neth. J. Zool. 35:720-30

174. Vet, L. E. M. 1988. The influence of learning on habitat location and acceptance parasitoids. Colloq. Inst. Natl. Rech. Agron. 48:29-34

175. Vet, L. E. M., De Jong, R, Van Giessen, W. A., Visser, J. H. 1990. A learning-related variation in electroantennogram responses of a parasitic wasp. Physiol. Entomol. 15:243-47

176. Vet, L. E. M., Groenewold, A. W. 1990. Semiochemicals and learning in parasitoids. J. Chem. Ecol. 16:3119-35

177. Vet, L. E. M., Lewis, W. J., Papaj, D. R., Van Lenteren, J. C. 1990. A variable-response model for parasitoid foraging behavior. J. Insect Behav. 3:471-90

178. Vet, L. E. M., Papaj, D. R. 1991. Effects of experience on parasitoid movement in odour plumes. Physiol. Entomol. In press

179. Vet, L. E. M., Van Alphen, J. J. M. 1985. A comparative functional approach to the host detection behaviour of parasitic wasps. I. A qualitative study on Eucoilidae and Alysiinae. Oikos 44:478-86

180. Vet, L. E. M., Wäckers, F. L., Dicke, 
M. 1991. How to hunt for hiding hosts: the reliability-detectability problem for foraging parasitoids. Neth. J. Zool. In press

181. Via, S. 1987. Genetic constraints on the evolution of phenotypic plasticity. In Genetic Constraints on Adaptive Evolution, ed. V. Loeschcke, pp: 47-71. Berlin: Springer Verlag. $188 \mathrm{pp}$.

182. Via, S. 1990. Ecological genetics and host adaptation in herbivorous insects: The experimental study of evolution in natural and agricultural systems. Annu. Rev. Entomol. 35:421-46

183. Vinson, S. B. 1976. Host selection by insect parasitoids. Annu. Rev. Entomol. 21:109-34

184. Vinson, S. B. 1981. Habitat location. See Ref. 111, pp. 51-77

185. Vinson, S. B. 1984. Parasitoid-host relationships. See Ref. 8, pp. 205-33

186. Vinson, S. B., Barfield, C. S., Henson, R. D. 1977. Oviposition behaviour of Bracon mellitor, a parasitoid of the boll weevil (Anthonomus grandis). II. Associative learning. Physiol. Entomol. 2:157-64

187. Vinson, S. B., Iwantsch, G. F. 1980. Host regulation by insect parasitoids. $Q$. Rev. Biol. 55:143-65

188. Visser, J. H. 1986. Host odor perception by phytophagous insects. Annu. Rev. Entomol, 31:121-44

189. Vité, J., Williamson, D. L. 1970. Thanasimus dubius: prey perception. J. Insect Physiol. 16:233-39

190. Waage, J. K. 1978. Arrestment responses of the parasitoid, Nemeritis canescens, to a contact chemical produced by its host, Plodia interpunctella. Physiol. Entomol. 3:135-46

191. Waage, J. K., Greathead, D. J., eds.
1986. Insect Parasitoids. London: Academic. $389 \mathrm{pp}$.

192. Wackers, F. L., Lewis, W. J. 1991. Olfactory and visual learning and their interaction in host site location by $\mathrm{Mi}$ croplitis croceipes. Biol. Control In press

193. Deleted in proof

194. Wall, C., Perry, J. N. 1983. Further observations on the responses of male pea moth, Cydia nigricana, to vegetation previously exposed to sexattractant. Entomol. Exp. Appl. 33:11216

195. Wardle, A. R. 1990. Learning of host microhabitat colour by Exeristes roborator (F.) (Hymenoptera: Ichnewnonidae). Anim. Behav. 39:914-23

196. Wardle, A. R., Borden, J. H. 1990. Learning of host microhabitat form by Exeristes roborator (F.) (Hymenoptera: Ichneumonidae), J. Insect Beh. 3:25163

197. Weseloh, R. M. 1981. Host location by parasitoids. See Ref. 111, pp. 79-95

198. Weseloh, R. M. 1987. Orientation behavior and effect of experience and laboratory rearing on responses of Cotesia melanoscela (Ratzeburg) (Hymenoptera: Braconidae) to gypsy moth silk kairomone. J. Chem. Ecol. 13:1493-1502

199. Whitman, D. C. 1988. Plant natural products as parasitoid cuing agents, In Biologically Active Natural Products, ed. H. G. Cutler, pp. 386-96. Washington, DC: Am, Chem, Soc.

200. Zaborski, E., Teal, P. E. A., Laing, J. E. 1987. Kairomone-mediated host finding by the spruce budworm egg parasite, Trichogramma minutum. J. Chem. Ecol. 13:113-22 